\title{
The Testis and Seminal Vesicle of the Farmed Male African Catfish: A Histological and Mucin Histochemical Observation
}

\author{
${ }^{1}$ Ikpegbu, E., ${ }^{2}$ Nlebedum, U. C., ${ }^{3}$ Nnadozie, O. And ${ }^{4}$ Agbakwuru, I.O. \\ ${ }^{1,2,3,4}$ Department of Veterinary Anatomy, Michael Okpara University of Agriculture Umudike, Abia State, \\ Nigeria.
}

\begin{abstract}
The histology of farmed African catfish was investigated. The testis was encapsulated by connective tissue fibres which contained blood vessels. The seminiferous tubules epithelium contained spermatogenic cells at various stages of development. The interstitial tissue of PAS positive connective tissue fibres contained blood vessels. The testis epithelium and interstitial tissue was AB negative. The seminal vesicle secreting epithelium was of simple cuboidal cells. This accessory gland was compartmentalized by connective tissue fibres. The compartments were filled by eosinophilic colloidal-like material. This seminal vesicle content was PAS positive but $A B$ negative. The absence of $A B$ positive materials in both the testis and seminal vesicle indicates the an alkaline environment is needed for optimum functioning of the male reproductive system in this species.
\end{abstract}

Key Words: Testis, Seminal Vesicle, Histology, Farmed African Catfish.

\section{Introduction}

The testis and seminal vesicle are organs of the teleost male reproductive system (Egami, 1960; Miller, 1984). The testis is the primary organ for spermatogenesis (Santos et al., 2001), while the function of the accessory gland -seminal vesicle though largely unclear, it is associated with sperm viability and storage (Weisel, 1949; Fishelson, 1991), secretion of steroids and pheromones, and increase in semen volume (Landsteiner et al., 1992; Singh and Joy, 1998).

Whereas there are information on the microanatomy of these organs in some teleosts like Corydoras aenus (Franceschini-Vincentini et al., 2007), sharptooth African catfish from lake kinneret in Israel and Blyde river South Africa (Fishelson et al.,1994), there is dearth of data from available literature on the histology of these organs from Nigerian commercial aquaculture their mucin histochemical reactions, hence this study . The information obtained from this study will be of importance to fish reproductive biologists and catfish breeders.

\section{Materials and Methods}

Seven male adult African catfish-Clarias gariepinus sourced from a commercial aquaculture in Eastern Nigeria were used for the study. They weighed an average of $900 \mathrm{~g}$ and measured a standard body length of $45 \mathrm{~cm}$ in length. The fish were euthanized with chloroform. The body cavity was cut open through the ventral surface and the alimentary tract dissected out. The specimen under study - the testis and seminal vesicle were excised and immediately fixed in $10 \%$ neutral buffered formalin.

The tissue was passed through graded ethanol, cleared in xylene, impregnated and embedded in paraffin wax. Sections $5-6 \mu$ m thick were obtained with Leitz microtome model 1512. They were stained with haematoxylin and eosin for light microscopy examination (Bancroft and Stevens, 1977). Mucins were demonstrated using Alcian blue (AB) at pH 2.5 (Steedman, 1950; Lev and Spicer, 1964) and Periodic acid Schiff (PAS) with and without prior digestion with diastase (Lillie and Greco, 1947, Ikpegbu et al., 2011). In addition, the PAS technique was employed in combination with $\mathrm{AB}$ for neutral and acid mucin (Bancroft and Stevens, 1977). Photomicrographs were taken with - Motican 2001 camera (Motican UK) attached to Olympus microscope.

\section{Results}

Grossly, the slender testis was seen in the abdomen as a pair lying parallel to the long axis of the body. It was the most caudal organ in the abdominal cavity. The rectum was seen lying in between the two testis. The seminal vesicle was seen as a bunch of finger-like projections from a central base attached to the caudal end of the testis.

Histologically, the tunica albugunea covering the testis was of loose connective tissue but the underlying dense collagen fibres divided the testis into trabeculae containing seminiferous tubules. The epithelium of the seminiferous tubules contained spermatogenic cells (fig.1). The seminal vesicle was covered by loose connective tissue. The transverse section revealed a secretory epithelium of simple cuboidal cells supported by basement membrane in each vesicle or compartment of the gland (fig.2). These vesicles were fluid 
filled. Each vesicle was surrounded by collagen fibres (fig. 2). The inter-vesicular cavity contained loose connective tissue and blood vessels (fig.4).

Mucin histochemistry revealed that the testis interstitial tissue was PAS positive, AB negative (fig.4), and magenta colour after combined AB-PAS procedure. The seminiferous tubules did not react to the mucin histochemical stains except slight magenta coloration to PAS reaction. The colloidal fluid in the seminal vesicle was PAS positive (fig.5 ), AB negative(fig.6 ), and magenta colour dominance after combined AB-PAS reaction.

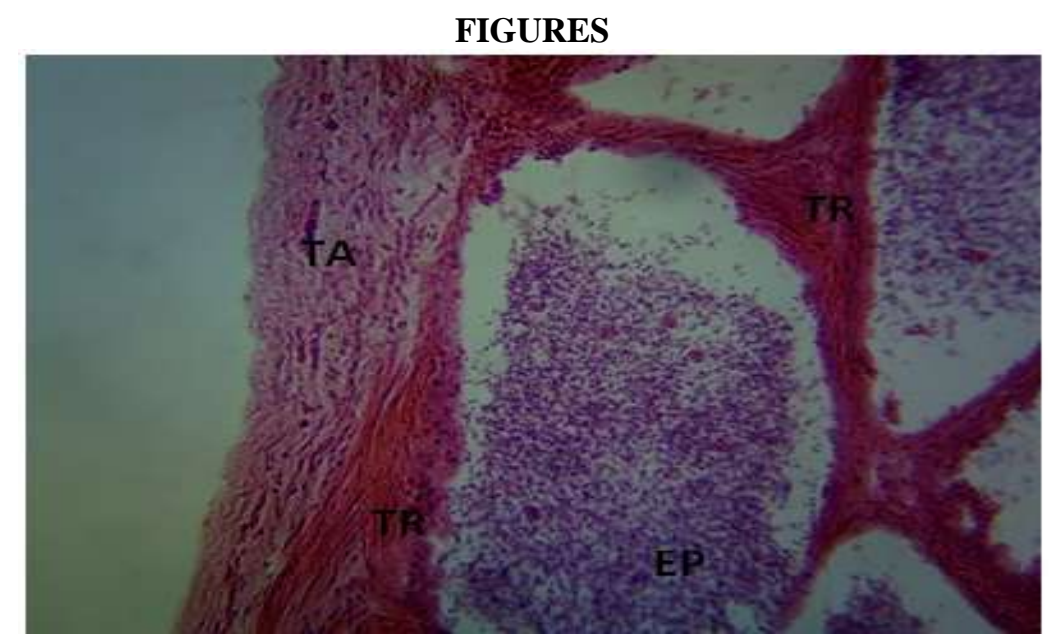

Fig. 1. Tranverse section of the Testis showing tunica albuginea of loose connective tissue TA, and seminferous tubules containing spermatogenic cells. Note the mediastinal collagen finbres. H\&E x400

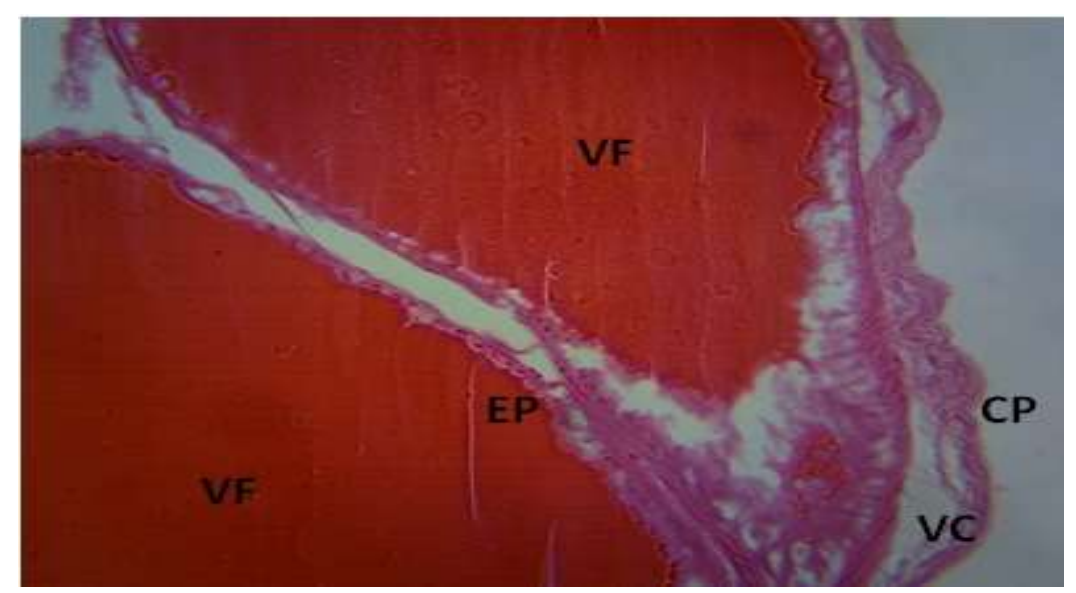

Fig.2. Transverse section of the seminal vesicle showing covering capsule of loose connective tissue CP, vesicular coat of denser collagen fibres VC. Note the simple cuboidal epithelium EP, and vesicular fluid VF. $\mathrm{H} \& \mathrm{E} \times 400$.

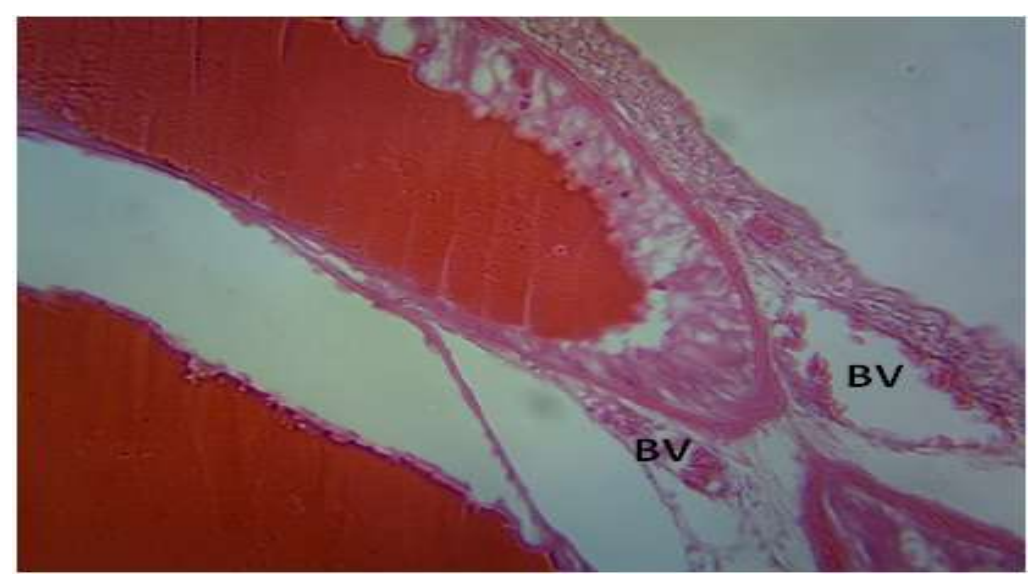

Fig.3. transverse section of seminal vesicle showing blood vessels BV, in the inter-vesicular cavity. H\&E x400. 


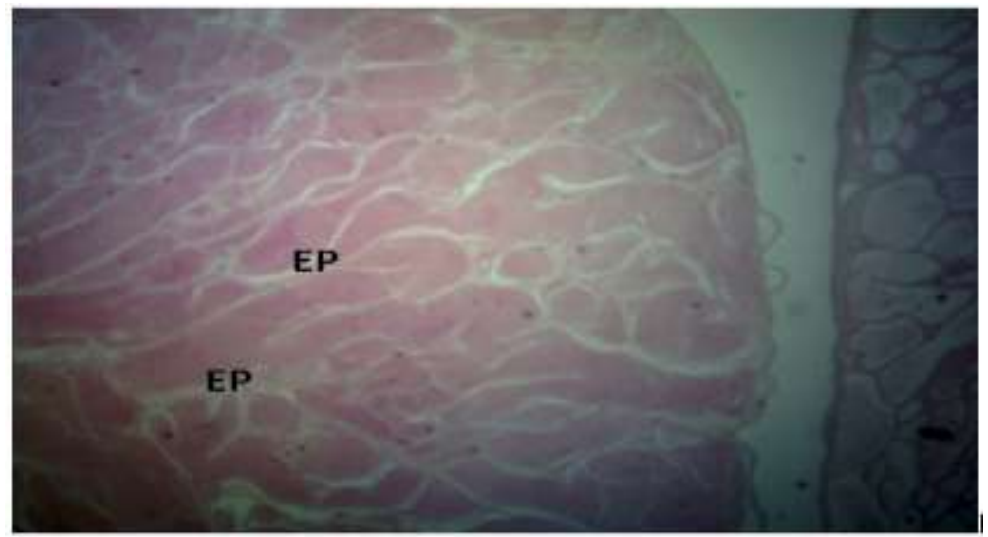

Fig. 4. Transverse section of the testis showing AB negative epithelium EP. AB x400.

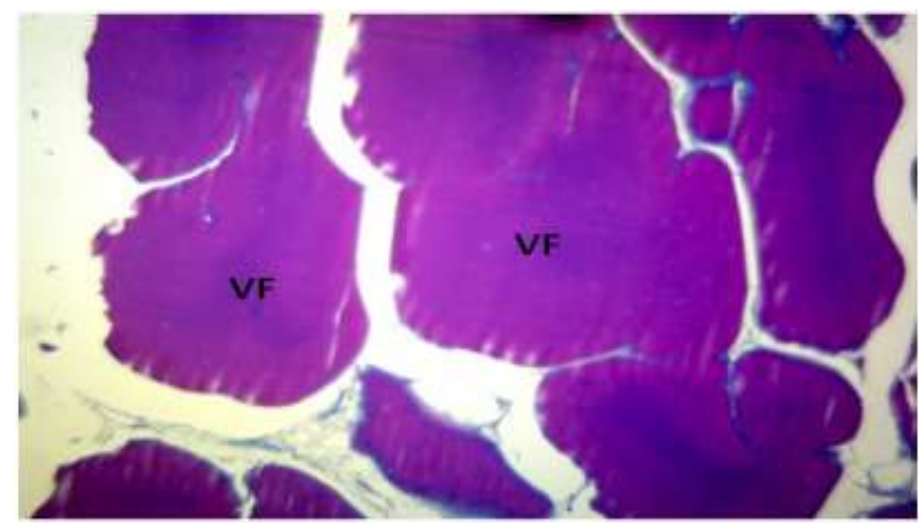

Fig.5. Transverse section of seminal vesicle showing PAS positive vesicular fluid VF. PAS x400

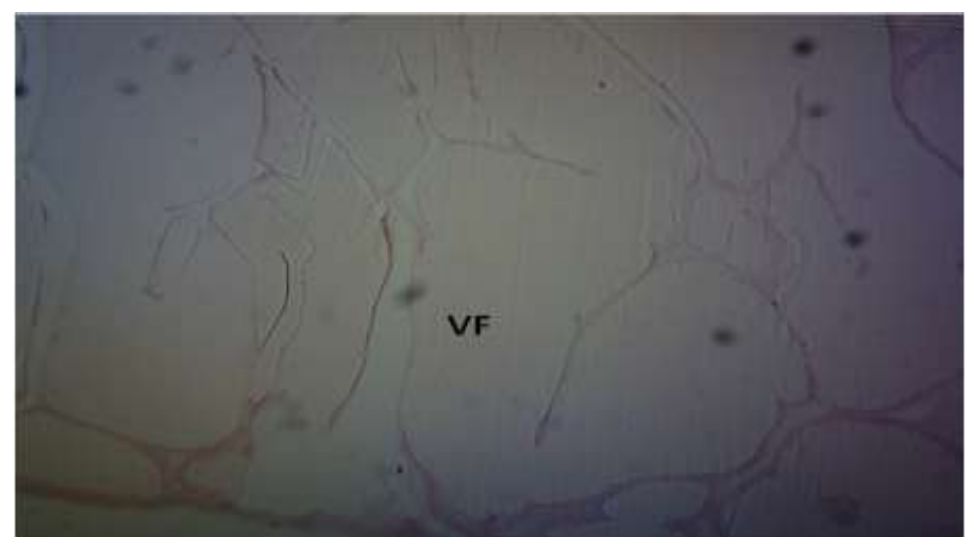

Fig.6. Transverse section of seminal vesicle showing AB negative vesicular fluid VF. AB x400

\section{Discussion}

The testis as a paired organ in the posterior part of the abdominal cavity as seen in this study has been documented in Parasilurus aristotelis (Iliadou and Fishelson, 1995). The connective tissue of the testis tunica albuginea is for protection of the seminiferous tubules. The seminiferous tubules germinal epithelium containing spermatogenic cells is the site of spermatogenesis. Some researchers have reported that some teleost testis may in addition to sperm cell formation serve as storage organ for mature sperm cells (Santos et al., 2001), and some have secretory function ( Loir et al ., 1989); but these two functions were not observed in this study. The secretory requirement for semen formation must be performed by the seminal vesicle present as an accessory organ of the male reproductive system. The simple cuboidal epithelium of the seminal vesicle must be the secretory producing the vesicular fluid. This fluid is believed to increase semen volume, sperm viability and may help in female attraction (Van Den Hurk et al., 1987; Lahnsteiner et al., 1992).

The positive reaction of the seminal fluid to PAS indicates the presence of glycogen moiety, which may be in the form of glycoproteins as elucidated by Iheringichthys labrosus (Santos et al., 2001). The negative reaction to $\mathrm{AB}$ by both testis and seminal vesicle indicates the absence of acid mucin in these organs. This suggests that 
acid mucin or acidic substances may be injurious to these organs affecting their reproductive health. This information should guide African catfish breeders in hatcheries and brood stock farmers to adequately regulate pond $\mathrm{pH}$ to avoid acidic environment if the viability of spermatozoa for fertilization will be guaranteed.

\section{References}

[1] Bancroft, J.D.and Stevens, A, Theory and practice of histological techniques. (Churchill Livingstone, New York, USA.1977.

[2] Egami, N, Comparative morphology of the sex characters in several species of Japanese gobies with reference to the effect of sex steroids on the characters. J. Faculty Univ. Tokyo 9, 1960, 67-100.

[3] Fishelson,L, Comparative cytology and morphology of seminal vesicle in male gobiid fishes. Jap. J. Ichthyol. $37,1991,50-63$.

[4] Fishelson,L., Van Vuren,J.H.J. and Tyran,A, Ontogenesis and ultrastructure of seminal vesicle of the catfish, Clarias gariepinus. J.Morphol.219, 1994, 59-71.

[5] Franceschini-Vicentini, I.B., Papa, L.P., Bombonato, M.T.S., Vinentini, C.A., Ribeiro, K. and Orsi A.M, A histological study of the seminal vesicle of the Armoured catfish Corydoras aenus. Anat. Histol. Embryol. 36, 2006, 111-115.

[6] Ikpegbu. E., Nlebedum, U.C., Nnadozie, O., and Agbakwuru, I, Fast Green FCF or Ehrlich's hematoxylin as counterstain to periodic acid Schiff reaction: A comparative study. Histologic 54, 2011, 29-30.

[7] Iliadou,K and Fishelson,L, Histology and cytology of the catfish Parasilurus aristotelis (Siluridae,Teleostei) from Greece. Jap. J. Ichthyol.41(4), 1995,447-454.

[8] J. E. Santos, N. Bazzoli,E. Rizzo, G. B. Santos, Morphofunctional organization of the male reproductive system of the catfish Iheringichthys labrosus (LuÈtken, 1874 Siluriformes:Pimelodidae). Tissue Cell, 33(5), 2001,533-540.

[9] Lahnsteiner, F., Seiwald, M., Patzner,R.A. and Ferrerol,E.A, The seminal vesicles of the male grass goby. Zoomorphol. 111, 1992,239-248.

[10] Lev, R. and Spicer, S.S, Specific staining of sulphated groups with alcian blue at low pH. J. Histochemistry Cytochemistry 12, 1964, $309-310$.

[11] Lillie, R.D. and Greco, J, Mact diastase ptyalin in place of saliva in the identification of glycogen. Staining Technique. 22, $1947,67-70$

[12] Loir, M., Cauty, C., Planquette, P. and Bail, P.Y, Comparative study of the male reproductive tract in seven families of SouthAmerican catfishes. Aquat. Living Resour., 2, 1989, 45- 56.

[13] Miller,P.J, The histology of gobiid fishes. In: G.M. Potts and R.J. Wotten (eds): Fish reproductive strategies and tactics. London Academic press pp119-153, 1984.

[14] Singh, M.S. and Joy K.P, A comparative study on the histochemical distribution of some enzymes related to steroid and glucuronide synthesis in seminal vesicle and testis of the catfish, Clarias batrachus. Zool. Sci.15, 1998, 955-961.

[15] Steedman, H.F, Alcian blue 8G: a new stain for mucin. Journal of Microscopic Science 91, 1950,477 - 479.

[16] Van Den Hurk, R., Resink, J.W. and Peute, J, The seminal vesicle of the African catfish, Clarias gariepinus: a histological, histochemical, enzyme-histochemical, ultrastructural and physiological study. Cell Tissue Res., 247, 1987, 573-582. 